\title{
Benzalkonium Chloride Intoxication Mimicking Herpes Zoster Encephalitis
}

\author{
Ekrem Güler, Şeref Olgar, Mehmet Davutoğlu, Mesut Garipardıç, Hamza Karabiber \\ Department of Pediatrics, Faculty of Medicine, Kahramanmaraş Sutcu Imam University, Kahramanmaraş, Turkey
}

\begin{abstract}
Benzalkonium chloride (BAC) is a frequently used disinfectant and its most well-known side effect is contact dermatitis. In this report, two children who had vesicular dermatitis, headache, lethargy, fever and encephalopathy mimicking Herpes zoster encephalitis were presented. Their consciousness level improved on the second day. From the medical history it was understood that the mother had applied $20 \%$ BAC solution to the scalps of two children. The aim of the presentation of this report is to draw attention to the fact that BAC application to the scalp for treating pediculosis capitis may resemble the herpes encephalitis clinical picture.
\end{abstract}

Key Words: Benzalkonium chloride, encephalopathy, intoxication, Herpes zoster mimicking encephalopathy, vesicular contact dermatitis

\section{Introduction}

Encephalitis is an acute inflammation of the meninges and cerebral tissue. Although the specific etiological agent is not identified in many instances, clinical and research experience indicate that viruses are the responsible pathogens for most infections. Enteroviruses cause more than $80 \%$ of all cases $(1,2)$. The other frequent viral causes are arboviruses and Herpes viruses. Herpes simplex encephalitis is very rare in healthy children younger than 10 years of age, whereas encephalitis, ranging from mild to severe, either accompanying or following Herpes zoster, is not uncommon $(3,4)$. However, a variety of non-infectious disorders may also be associated with CNS inflammation and have manifestations similar to those associated with viral meningoencephalitis. Some of these disorders include malignancy, collagen vascular diseases, intracranial hemorrhage and exposure to certain drugs or toxins (1-3). However, in this case report we describe vesicular exanthema and encephalopathy mimicking a Herpes simplex virus encephalitis as a result of benzalkonium chloride (BAC) application to the scalp to treat pediculosis capitis.

\section{Case Report}

A 7-year-old boy was admitted with headache, fever, lethargy and vesicular exanthema on the capitis and back of the neck. Initially, the medical history was given by the patient's uncle and drug contamination was denied by both the patient and his family.

The previous day, the patient had begun complaining of itching and a burning sensation on his scalp, and he had a fever. The next day, he had become less responsive to those around him and he was referred to our hospital.
On physical examination, he was lethargic and sleepy. His Glasgow coma score was 12 (E5M4V3) and his body temperature was $38.3^{\circ} \mathrm{C}$ (axillary). The scalp was hyperemic and there was a vesicular rash present. The vesicles varied in size and some had been damaged by itching. The discharged fluid from the vesicles was clear. The patient's scalp was sensitive to the touch, and there was clear demarcation between the affected skin and healthy skin (Figure 1). On neurological examination, he had neck stiffness and positive Kerning reflex. In addition, his fundoscopic examination revealed papilledema and cranial tomographic imaging (CT) supported brain edema.

On laboratory examination, complete blood count, liver and kidney function tests, and routine biochemical tests were all found to be within normal limits. C-reactive protein was $13 \mathrm{mg} / \mathrm{dl}$ (normal limits $<3 \mathrm{mg} / \mathrm{dl}$ ). Erythrocyte sedimentation rate was $16 \mathrm{~mm} /$ hour.

The patient was diagnosed with suspicious herpetic viral encephalitis and, due to brain edema, cerebrospinal fluid examination was not performed on admission. However, due to suspicion of Herpes encephalitis, anti-edema therapy was applied and acyclovir was given by intravenous infusion empirically. His consciousness level improved on the second day of admission and a lumbar puncture was performed. His serum and cerebrospinal fluid (CSF) samples were analyzed for specific viral markers. There were no antibodies against Herpes simplex and Varicella zoster viruses. CSF analysis showed a glucose level of $78 \mathrm{mg} / \mathrm{dl}$ (with a blood glucose level of 117 $\mathrm{mg} / \mathrm{dl}$ ) and protein $19 \mathrm{mg} / \mathrm{dl}$, and microscopic examination showed no leukocytes or erythrocytes.

As he had been on therapy, his sister was admitted to hospital due to similar skin and neurologic finding (Figure 2). She was a 12-year-old girl and had vesicular lesions on the 
post-auricular region and neck, and her fundoscopic examination revealed papilledema. Her mother accompanied the patient and explained that she had spread 20\% BAC solution (Dezen ${ }^{\circledR}$ Vetaş Veteriner ve Tarim ilaçları AS, Istanbul, Turkey) onto the children's scalps as treatment for pediculosis capitis. Thereafter, Herpes encephalitis was ruled out and the first case's acyclovir was discontinued. The girl was treated with anti-edema therapy and acyclovir was not administered. The first case's CSF Gram staining, acid-fast bacilli, routine bacterial culture and cryptococcal smears were negative, and both patients were discharged on the fourth day.

\section{Conclusions}

A number of clinical conditions that cause CNS inflammation mimic viral meningoencephalitis. However, prognosis depends upon the severity of the clinical illness, the specific etiology and the age of the child. The CSF is characterized by pleocytosis, and the absence of microorganisms on Gram stain and routine culture (1). The most important groups of infectious agents causing CNS inflammation are bacteria and viruses. Herpes simplex must be considered in the differential diagnosis of all cases with encephalitis. Until the confirmation of the differential diagnosis, acyclovir should be administered empirically, since the rate of mortality and sequelae decreases in herpes simplex encephalitis with this approach. In the first case, fever, encephalopathy and vesicular exanthema suggested Herpes simplex encephalitis, and this diagnosis continued to be suspected until after acyclovir had been administered

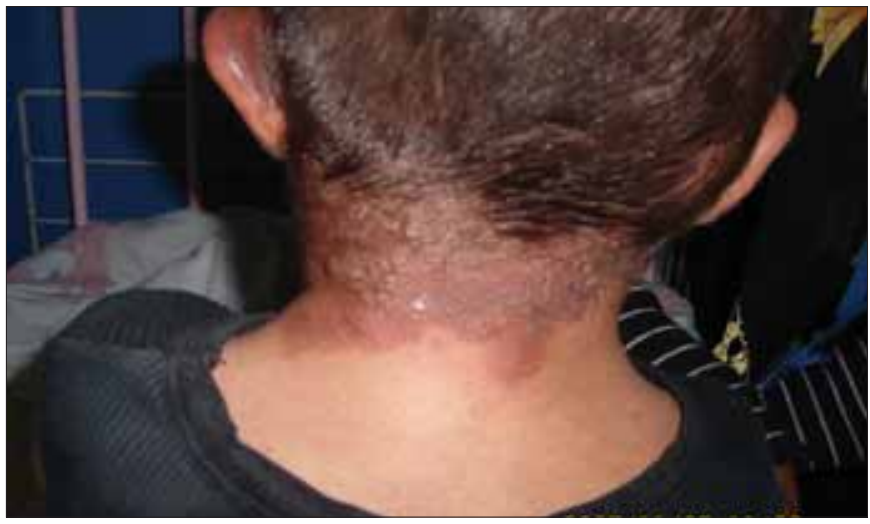

Figure 1. First case-vesicular rashes surrounding edema on scalp and back of the neck

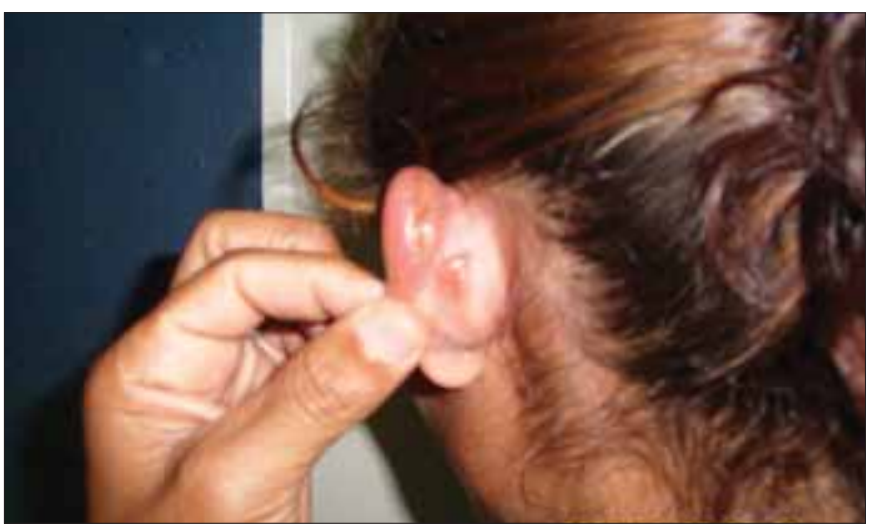

Figure 2. Second case-bullous lesions on the back of the pinna empirically. However, a variety of non-infectious disorders may also be associated with CNS inflammation, and have manifestations similar to those associated with viral meningoencephalitis and some other disorders, including malignancy, collagen vascular diseases, intracranial hemorrhage and exposure to certain drugs or toxins (1). This case report shows that one such drug is BAC, which is normally used as an antibacterial, antifungal and antiviral disinfectant. In addition, it is used as a preservative in various medical preparations in concentrations ranging from $0.01 \%$ to $0.05 \%(5-7)$. However, acute irritant contact dermatitis induced by cutaneous exposure has been frequently reported (8). In the previously reported cases of vesicular exanthema (contact dermatitis), fever and encephalopathy due to BAC were not cited. BAC is an ammonium quaternary detergent that binds to cytoplasmic membrane and subsequently causes cytoplasmic membrane impairment and $\mathrm{K}$ ions releases. $\mathrm{K}$ ions and the other cytoplasmic membrane products affect cell proteins denaturation and enzyme system disturbances (9). The encephalopathy might be related to this toxic effect. However, contact area size, contact amount, drug concentration and contact duration were important because it is normally used at $1 / 100$ or $1 / 1000$ concentrations for surface disinfection, and in our cases it was used at surface concentration too. In addition, it was applied to the neck and scalp.

Animal drugs and disinfectants are frequently used to treat human diseases in rural areas by farmers. However, dosage and metabolism of such drugs differ considerably and cause severe intoxication in humans. In conclusion, spreading BAC over the scalp can cause vesicular exanthema and encephalopathy mimicking Herpes zoster encephalitis, and must not be used for children's diseases.

\section{Conflict of Interest}

No conflict of interest was declared by the authors.

\section{References}

1. Johnston MV. Encephalopathies. In: Behrman RE, Kliegman RM, Arvin AM, eds. Nelson Textbook of Pediatrics. 17th edition. Philadelphia: WB Saunders 2003;2023-9.

2. Richard J. Whitley; Viral infections of the central nervous system. In: Gershon AA, Hotez PJ, Katz SL, eds. Krugman's Infectious Diseases of Children. 11th edition. St Louis: Mosby 2003;855-76.

3. Myers MG, Stanberry LR, Seward JF. Varicella-Zoster Virus. In: Behrman RE, Kliegman RM, Arvin AM, eds. Nelson Textbook of Pediatrics. 17th edition. Philadelphia: WB Saunders, 2003;1057-62.

4. Sigaloff KC, de Fijter CW. Herpes zoster-associated encephalitis in a patient undergoing CAPD: case report and literature review. Perit Dial Int 2007:27:391-4.

5. Deutschle T, Porkert U, Reiter R, Keck T, Riechelmann H. In vitro genotoxicity and cytotoxicity of benzalkonium chloride. Toxicol in Vitro 2006;20:1472-7. [CrossRef]

6. Bernstein IL. Is the use of benzalkonium chloride as a preservative for nasal formulations a safety concern? A cautionary note based on compromised mucociliary transport. J Allergy Clin Immunol 2000;105:39-44. [CrossRef]

7. Gurol Y, Kocagoz S. Comparasion of the efficacy of two new disinfectants with other disinfectants. Turkiye Klinikleri J Med Sci 2008;28:128-32.

8. Fuchs T, Meinert A, Aberer W, Bahmer FA, Peters KP, Lischka GG, Schulze-Dirks A, Enders F, Frosch PJ. Benzalkonium chloride--a relevant contact allergen or irritant? Results of a multicenter study of the German Contact Allergy Group. Hautarzt 1993;44:699-702.

9. http://www.vetas.com.tr/dokumanlar/1189846868.pdf [CrossRef] 